\title{
Fire Risk Assessment in Healthcare Settings: Application of FMEA Combined with Multi-Criteria Decision Making Methods
}

\author{
Fateme Omidvari $\left(\mathbb{D},{ }^{1}\right.$ Mehdi Jahangiri $\left(\mathbb{D},{ }^{1}\right.$ Reza Mehryar $\left(\mathbb{D},{ }^{2}\right.$ Moslem Alimohammadlou (D), \\ and Mojtaba Kamalinia (iD ${ }^{1}$ \\ ${ }^{1}$ School of Health, Department of Occupational Health, Shiraz University of Medical Sciences, Shiraz, Iran \\ ${ }^{2}$ School of Mechanic and Aerospace Engineering, Department of Heat and Fluids, Shiraz University of Technology, Shiraz, Iran \\ ${ }^{3}$ School of Economics, Management and Social Sciences, Department of Management, Shiraz University, Shiraz, Iran \\ Correspondence should be addressed to Mehdi Jahangiri; jahangiri_m@sums.ac.ir
}

Received 25 July 2020; Revised 21 September 2020; Accepted 25 September 2020; Published 19 October 2020

Academic Editor: Samuel Yousefi

Copyright (c) 2020 Fateme Omidvari et al. This is an open access article distributed under the Creative Commons Attribution License, which permits unrestricted use, distribution, and reproduction in any medium, provided the original work is properly cited.

\begin{abstract}
Fire is one of the most dangerous phenomena causing major casualties and financial losses in hospitals and healthcare settings. In order to prevent and control the fire sources, first risk assessment should be conducted. Failure Mode and Effect Analysis (FMEA) is one of the techniques widely used for risk assessment. However, Risk Priority Number (RPN) in this technique does not take into account the weight of the risk parameters. In addition, indirect relationships between risk parameters and expert opinions are not considered in decision making in this method. The aim is to conduct fire risk assessment of healthcare setting using the application of FMEA combined with Multi-Criteria Decision Making (MCDM) methods. First, a review of previous studies on fire risk assessment was conducted and existing rules were identified. Then, the factors influencing fire risk were classified according to FMEA criteria. In the next step, weights of fire risk criteria and subcriteria were determined using Intuitionistic Fuzzy Multiplicative Best-Worst Method (IFMBWM) and different wards of the hospital were ranked using Interval-Valued Intuitionistic Fuzzy Combinative Distance-based Assessment (IVIFCODAS) method. Finally, a case study was performed in one of the hospitals of Shiraz University of Medical Sciences. In this study, fire alarm system (0.4995), electrical equipment and installations (0.277), and flammable materials (0.1065) had the highest weight, respectively. The hospital powerhouse also had the highest fire risk, due to the lack of fire extinguishers, alarms and fire detection, facilities located in the basement floor, boilers and explosive sensitivity, insufficient access, and housekeeping. The use of MCDM methods in combination with the FMEA method assesses the risk of fire in hospitals and health centers with great accuracy.
\end{abstract}

\section{Introduction}

Fire is one of the most dangerous phenomena causing major casualties and financial losses [1]. Hospitals and medical centers are among the places where a large number of fires occur annually [2]. According to statistics from the US National Fire Protection Agency (NFPA), between 2011 and 2015, 5750 fires occurred each year in the US hospitals [3]. Incidents around the world include the 1929, 1949, and 1950 fires in the United States that killed 125, 74, and 41 people, respectively, and the 2005 fire in Costa Rica with 19 deaths, the 2011 fire in India with 91 deaths, 2013 fires in Russia with
38 deaths, 2013 fires in Japan with 10 deaths [4], and fires in 2016 at 17 Shahrivar Hospital in Borazjan and Razi Hospital in Tabriz with one death [5]. Fire occurs in hospitals for many reasons, the most important sources of which are trash fires, clothes, and curtains in nurses' rooms, spark lights in nurses' rooms, sparks from fluorescent lamps in warehouses, defects in electrical systems and heating appliances, smoking in personnel restrooms, kitchen fires, and intentional fires at the site of waste collection [2]. In hospitals and healthcare centers, fire safety is very important because evacuation of people with disabilities and illnesses may be slower, resulting in more deaths and financial damage. Therefore, fire risk assessment is 
important for identifying fire sources and selecting and evaluating fire control methods $[6,7]$.

Different methods have been used to assess fire risk in hospitals, including Analytic Hierarchy Process (AHP) [8], checklist [9], NFPA101 [1, 10], Fire Risk Assessment Method for Engineering (FRAME) [2, 11-14], and Failure Mode and Effect Analysis (FMEA) [5]. One of the methods widely used in hazard risk assessment, including the fire risk assessment, is FMEA. The method was first formally applied in the US aerospace industry in the 1960s. In this method, all paths that may be malfunctioning under the system and the effect of these defects on the system are investigated [15]. Traditional FMEA used the Risk Priority Number (RPN) along with three parameters of detectability, probability, and severity to rank defects [15-17]. However, traditional FMEA has some disadvantages as follows:

(1) In this method, the values of Severity (S), Detectability (D), and Probability of occurrence (P) are the same, although their degree of significance may vary, so different combinations of $\mathrm{S}, \mathrm{P}$, and $\mathrm{D}$ can result in an RPN value, defects with the same RPN may be due to different factors and the nature of the risks created $[16,17]$

(2) The FMEA calculation does not consider the indirect relationships between the parameters affecting risk estimation [16]

(3) The parameters affecting the calculation of FMEA do not cover the whole range of failure state factors such as errors, inconsistencies and uncertainties [16]

Many studies have found that the FMEA method alone is not sufficient and should be combined with other methods to address the above limitations: Omidvari et al. [7] and SarAbadani and Ghiysai [18] used the AHP method to weigh the risk parameters. However, AHP has its own limitations and was applied to the BWM method by Rezaei [19] in 2015. The advantages of the BWM method over the AHP are that BWM requires fewer comparisons and its final weights are highly reliable and provides more consistent comparisons. Moreover, in the BWM pair comparison matrix, only integer numbers are used which are much easier to use [19, 20]. Song et al. improved the FMEA method by rough set theory to assess human risk factors, which does not need much prior information, but the proposed model assumes that each failure mode is independent of one another [21]. Rezaee et al. [22] and Chang et al. [23] used the fuzzy Data Envelopment Analysis (DEA) model combined with FMEA for risk analysis but this study did not consider the casual relationship between risks. There are other studies that have used MCDM techniques in combination with MCDM methods including fuzzy FMEA [24-26], fuzzy set theory and MULTIMOORA [27], fuzzy linguistic theory [28], new fuzzy FMEA based on fuzzy set theory and the VIKOR $[29,30]$, interval 2-tuple hybrid weighted distance [31], interval-valued intuitionistic fuzzy sets and the Multi-Attributive Border Approximation Area Comparison (MABAC) method [32], Triangular Fuzzy Number (TFN) with the BWM and fuzzy Multi-Objective Optimization by Ratio Analysis (fuzzy MOORA) [33].
As the review of the above studies has shown, the MCDM techniques used in previous studies have not been able to consider all the limitations of FMEA. Moreover, none of the above mentioned studies have been conducted specifically to assess fire risk in hospital and healthcare settings. Therefore, a new approach based on Intuitionistic Fuzzy Multiplicative Best-Worst Method (IFMBWM) and Interval-Valued Intuitionistic Fuzzy Combinative Distance-Based Assessment (IVIFCODAS) was proposed for fire risk assessment in healthcare buildings. Intuitionistic fuzzy was used to eliminate the limitations of uncertainty in the FMEA because this set examines uncertainties better than the fuzzy method. The advance of intuitionistic fuzzy which first introduced by Atanasovo in 1986 [34] over the fuzzy introduced by Zadeh in 1965 [35] is that in the fuzzy set theory, the membership degree of the fuzzy number is between zero and one, and the degree of nonmembership is only a complement of the membership degree of one. But when the decision maker expresses his opinion in the form of an element of the fuzzy set, he/she does not consider the nonmembership degree as a complement to the membership degree of one, and indeed there may be some degree of doubt. Therefore, intuitionistic fuzzy sets are introduced which are represented by two concepts of membership degree and nonmembership degree. These sets are a good tool for describing ambiguous and inaccurate decision information and addressing the uncertainty and ambiguity of the decision making process [36]. The CODAS method, introduced by Ghorabaee et al. in 2016 [37], is one of the MCDM techniques in which the relationships of indirect parameters are considered to calculate the utility of alternatives which makes the results closer to reality compared to fuzzy MOORA, MULTIMOORA, VIKOR, and fuzzy VIKOR. IFBWM have also been applied to determine the weight of the FMEA criteria and eliminate the limitations of AHP, fuzzy FMEA, and TFNBWM methods.

In the continuation of the article, after explaining the details of the proposed approach in this study, the results of applying this approach to fire risk assessment in a medical building will be presented in a case study.

The rest of this study is organized as follows: In Section 2, the proposed approach of the study including identification of risk factors for fires in healthcare buildings, determining the weight of the criteria and ranking the hospital wards based on fire risk, has been described. A case study is utilized to demonstrate the proposed method in Section 3. Finally, Section 4 presents the conclusions and limitations of the study.

\section{Method}

The study was conducted in two main stages. In the first stage, the fire risk assessment method was developed based on the FMEA method and MCDM techniques. Secondly, this method was used in a case study to assess the risk of fire in the hospital. Figure 1 shows the phases of the proposed approach in this study.

2.1. Developing the Fire Risk Assessment Method. In this section, a proposed fire risk assessment method, based on FMEA combined with MCDM methods, has been described. 


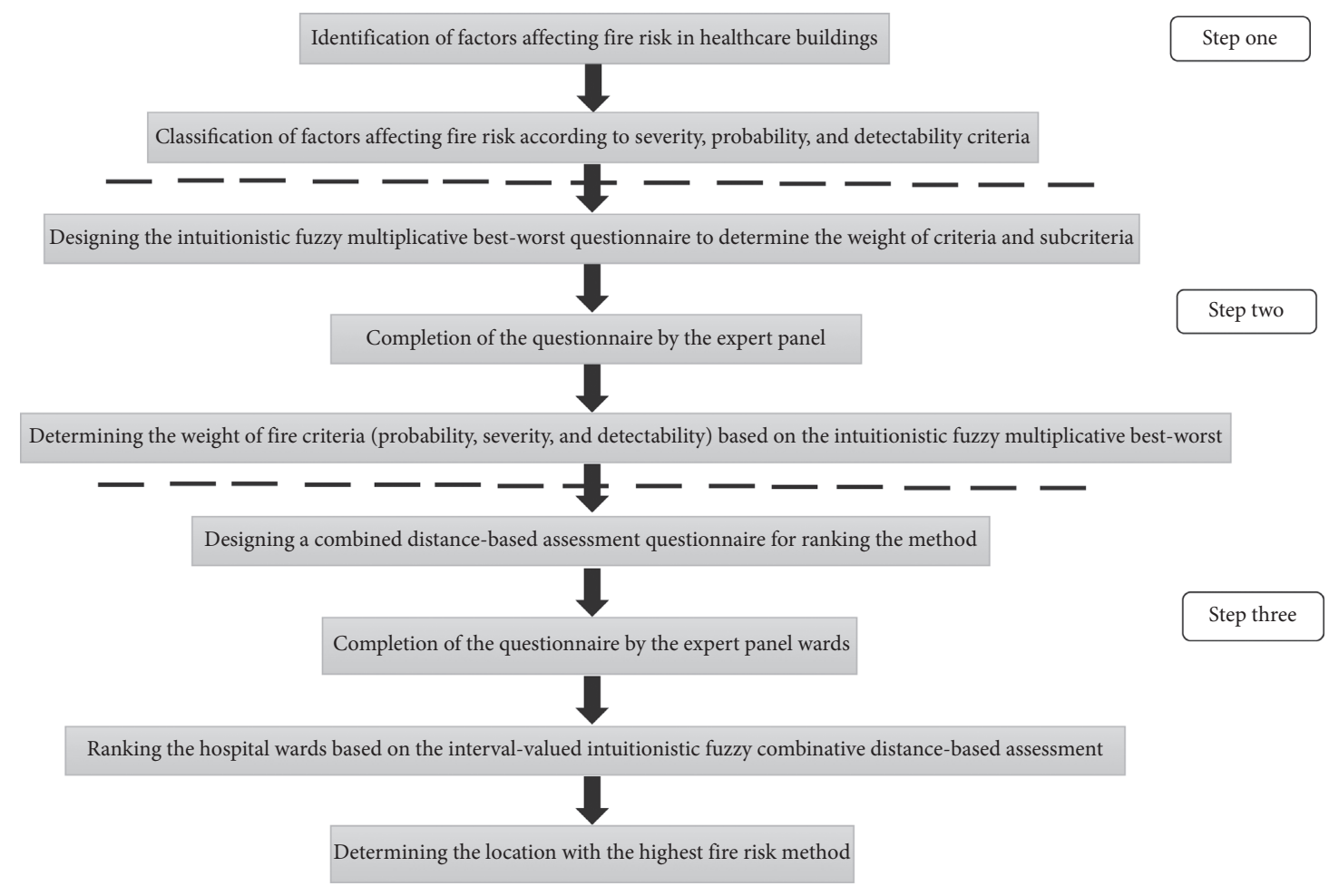

Figure 1: Proposed approach steps.

2.1.1. Identification of Risk Factors for Fires in Healthcare Buildings. At this stage, risk factors for fires in healthcare buildings were extracted from previous studies [6, 7, 38-45], using safe hospital standards [46] and national building regulation [47] and consulting with a panel of ten experts consisting of occupational safety and health experts working in hospitals and hospital inspectors; the identified factors were classified according to the criteria of the FMEA method including probability, severity, and detectability of fire.

2.1.2. Determining the Weight of the Criteria and Subcriteria. At this stage, the importance and weight of each fire risk criteria and subcriteria were determined using the IFMBWM, as follows [48]:

(1) Forming Expert Comparison Matrix. Fire risk criteria and subcriteria were provided to the panel of experts using IFMBWM questionnaire and they were asked to compare the importance of each criteria and subcriteria by pairwise comparison in terms of probability, severity, and detectability. Comparisons were made using linguistic terms to determine the importance of each criterion based on intuitionistic fuzzy numbers (Table 1). Then, comparisons matrix of experts was made according to their responses.

For brevity to use Table 1, we denote $N=\{1,2, \cdots, n\} . X=\left\{x_{1}, x_{2}, \cdots, x_{n}\right\}$. and $S=\{1,2, \cdots, s\}$.

Let $X$ be a fixed set, then an intuitionistic fuzzy multiplicative set is defined as follows:

$$
\mathrm{D}=\left\{\left\langle x \cdot \mu_{j}(x) \cdot v_{j}(x)\right\rangle \mid x \in X\right\}
$$

which assigns to each element $x \in X$, a membership degree $\mu_{j}(x)$, and a nonmembership degree $\nu_{j}(x)$ with the following condition: $1 / 9 \leq \mu_{j}(x) \cdot v_{j}(x) \leq 9 \cdot \mu_{j}(x) \nu_{j}(x) \leq 1 . \forall_{x} \in X$.
TABle 1: Linguistic terms to determine the significance of each criterion based on intuitionistic fuzzy numbers [49].

\begin{tabular}{lcccc}
\hline Verbal expressions & Score & $\mu$ & $\nu$ & $\pi$ \\
\hline Equally important & 1 & 0.02 & 0.18 & 0.80 \\
Intermediate & 2 & 0.06 & 0.23 & 0.70 \\
Moderately more important & 3 & 0.13 & 0.27 & 0.60 \\
Intermediate & 4 & 0.22 & 0.28 & 0.50 \\
Strongly more important & 5 & 0.33 & 0.27 & 0.40 \\
Intermediate & 6 & 0.47 & 0.23 & 0.30 \\
Very strong important & 7 & 0.62 & 0.18 & 0.20 \\
Intermediate & 8 & 0.80 & 0.10 & 0.10 \\
Extremely more important & 9 & 1.00 & 0.00 & 0.00 \\
& $1 / 2$ & 0.23 & 0.06 & 0.7 \\
& $1 / 3$ & 0.27 & 0.13 & 0.6 \\
& $1 / 4$ & 0.28 & 0.22 & 0.5 \\
Scale & $1 / 5$ & 0.27 & 0.33 & 0.4 \\
& $1 / 6$ & 0.23 & 0.47 & 0.3 \\
& $1 / 7$ & 0.18 & 0.62 & 0.2 \\
& $1 / 8$ & 0.10 & 0.80 & 0.1 \\
& $1 / 9$ & 0.00 & 1.00 & 0.00 \\
\hline
\end{tabular}

$\mu$ : degree of membership; $v$ : degree of nonmembership; $\pi$ : degree of doubt.

(2) Formation of Intuitionistic Fuzzy Aggregate Matrix. At this stage, the intuitionistic fuzzy matrix was formed using the following equation:

$$
\begin{aligned}
A & =\operatorname{IIFW} A_{W}\left(A^{(1)}, A^{(2)}, \cdots, A^{(S)}\right) \\
& =\left(1-\prod_{j=1}^{n}\left(1-\mu_{j}\right)^{w_{j}} \cdot \prod_{j=1}^{n}\left(v_{j}\right)^{w_{j}}\right),
\end{aligned}
$$


where $\mu$ represents the membership degree and $v$ represents the nonmembership degree and $w$ represents the weight of each expert.

(3) Determining the Most and the Least Important Criteria. After forming the matrix network of comparisons, the most and least important criteria were finally determined. In this step, according to Figure 2, all the effects (degree of membership and nonmembership) of the matrix aggregated between two criteria were recursively shown. In this case, there will be two reciprocal vectors between two criteria that were compared between them. Then, by selecting the vector with the highest membership, the other vector will be deleted.

(4) Determining the Weight for Membership Degree Part. At this step, the optimal weights of the set of vectors for membership degree were calculated by the following equation:

$$
\left(\tau_{1}^{*} \cdot \tau_{2}^{*} \cdot \cdots \cdot \tau_{n}^{*}\right)^{\mathrm{T}}
$$

$$
\begin{array}{ll}
\text { Min } & \xi \\
\text { s.t. } & \left|\frac{\tau_{\text {best }}}{\tau_{j}}-\rho_{\text {best. } j}\right| \leq \xi, \\
& \left|\frac{\tau_{j}}{\tau_{\text {worst }}}-\rho_{j . \text { worst }}\right| \leq \xi, \\
& \sum_{j=1}^{n} \tau_{j}=1, \\
& \tau_{1} \geq \tau_{2} \geq \cdots \geq \tau_{n}, \\
& \xi \geq 0, \tau_{j} \geq 0 . \text { for all } j \in N,
\end{array}
$$

where $\tau_{j}^{*}$ is the membership degree of importance.

(5) Determining the Nonmembership Degree Weights. The optimal weights of the set of vectors for the nonmembership degree were calculated using the following equation:

$$
\begin{array}{ll} 
& \left(v_{1}^{*}, v_{2}^{*}, \cdots, v_{n}^{*}\right)^{T}, \\
\min \quad \zeta & \left|\frac{v_{\text {best }}}{v_{j}}-\sigma_{\text {best. } j}\right| \leq \zeta, \\
& \left|\frac{v_{j}}{v_{\text {worst }}}-\sigma_{j . \text { worst }}\right| \leq \zeta, \\
& \sum_{j=1}^{n} v_{j}=1, \\
& v_{1} \leq v_{2} \leq \cdots \leq v_{n}, \\
& \zeta \geq 0, v_{j} \geq 0 . \text { for all } j \in N,
\end{array}
$$

where $v_{j}^{*}$ is the nonmembership degree of importance.

(6) Calculating the Consistency Ratio (CR). CR can be taken as a measure to check the reliability of the weights. At

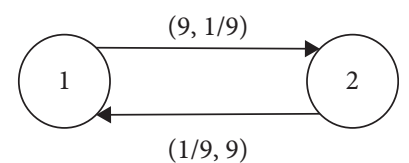

(a)

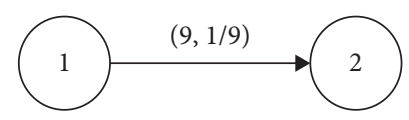

(b)

Figure 2: Comparison between two criteria.

first, we identified the values of $\mu_{\text {best.worst }} \in\{1,2,3, \cdots, 9\} . \nu_{\text {best.worst }} \in\{1,1 / 2,1 / 3, \cdots, 1 / 9\}$.

Then, we obtained the smallest consistency and the corresponding maximum possible values of $\delta^{*}$ (i.e., $\max \delta$ ) and $\varepsilon^{*}($ i.e., $\max \varepsilon$ ) using Table 2. These maximum values can be considered as the consistency index $1\left(\mathrm{CI}_{1}\right)$ and the consistency index $2\left(\mathrm{CI}_{2}\right)$. Consequently, by maximizing the two ratios of the optimal values $\delta^{*}$ to $\mathrm{CI}_{1}$, and $\varepsilon^{*}$ to $\mathrm{CI}_{2}$, we can obtain the consistency ratio as shown in equation (5).

$$
\text { Consistency ratio }=\max \left\{\frac{\xi^{*}}{\mathrm{Cl}_{1}} \cdot \frac{\zeta^{*}}{\mathrm{Cl}_{2}}\right\} .
$$

The CR is a number between 0 and 1 that the smaller the value, the greater the compatibility [48].

2.2. Ranking the Hospital Wards Based on Fire Risk. After determining the weight of the criteria, the different hospital wards were ranked using the IVIFCODAS method as follows.

2.2.1. Forming the Fuzzy Decision Matrix. First, using a questionnaire, experts were asked to rate the hospital wards according to the criteria of probability, severity, and detectability using linguistic terms in determining the importance of the alternative based on Interval-Valued Intuitionistic Fuzzy (IVIF) numbers (Table 3). Then, the IVIF decision matrix $\left(\widetilde{X}_{l}\right)$ was computed for each expert and the fuzzy decision matrix will be calculated according to the following equation:

$$
\begin{aligned}
\widetilde{X}_{l}=\left[\widetilde{X}_{i j l}\right]_{n \times m} & =\left[\begin{array}{ccc}
\widetilde{X}_{11 l} & \cdots & \widetilde{X}_{1 \mathrm{ml}} \\
\vdots & \ddots & \vdots \\
\widetilde{X}_{\mathrm{n} 11} & \cdots & \widetilde{X}_{\mathrm{nml}}
\end{array}\right], \\
\widetilde{X}_{i j} & =\left(\left[\mu_{i j}^{-}, \mu_{i j}^{+}\right],\left[\begin{array}{ll}
v_{i j}^{-}, & v_{i j}^{+}
\end{array}\right]\right),
\end{aligned}
$$

where $\tilde{X}_{i j l}$ represents the value of the IVIF function $i$ th alternative $(i \in\{1,2, \cdots, n\})$ with the $j$ th criteria $(j \in\{1,2, \cdots, m\})$ and $l$ th decision maker $(l \in\{1,2, \cdots, K\})$. For each $x \in X, \mu_{i j}$ and $\nu_{i j}$ are closed intervals whose lower and upper end points are denoted by $\mu_{i j}^{-}, \mu_{i j}^{+}, \nu_{i j}^{-}$and $\nu_{i j}^{+}$.

Determining the IVIF weight of each criteria: 
TABle 2: Compatibility index $1\left(\mathrm{CI}_{1} \cdot \max \delta\right)$ and compatibility index $2\left(\mathrm{CI}_{1} \cdot \max \varepsilon\right)$.

\begin{tabular}{llllllllll}
\hline$\rho_{\text {best. worst }}$ & 1 & 2 & 3 & 4 & 5 & 6 & 7 & 8 & 9 \\
\hline
\end{tabular}

\begin{tabular}{llllllllll}
\hline $\mathrm{CI}_{1} \cdot \max \delta$ & 0.00 & 0.44 & 1.00 & 1.63 & 2.30 & 3.00 & 3.73 & 4.47 & 5.23 \\
\hline
\end{tabular}

\begin{tabular}{llllllllll}
\hline$\sigma_{\text {best.worst }}$ & $1 / 9$ & $1 / 8$ & $1 / 7$ & $1 / 6$ & $1 / 5$ & $1 / 4$ & $1 / 3$ & $1 / 2$ & 1 \\
\hline
\end{tabular}

\begin{tabular}{llllllllll}
\hline $\mathrm{CI}_{1} \cdot \max \mathcal{E}$ & 0.08 & 0.08 & 0.09 & 0.10 & 0.11 & 0.12 & 0.12 & 0.12 & 0.00
\end{tabular}

TABle 3: Linguistic terms in determining the importance of the alternative based on intuitionistic interval fuzzy numbers [50].

\begin{tabular}{lc}
\hline Verbal phrases & IVIF numbers \\
\hline Certain low $(\mathrm{CL})$ & $\langle[0.1,0.25],[0.65,0.75]\rangle$ \\
Low $(\mathrm{L})$ & $\langle[0.2,0.35],[0.55,0.65]\rangle$ \\
Exactly equal $(\mathrm{EE})$ & $\langle[0.5,0.5],[0.5,0.5]\rangle$ \\
High $(\mathrm{H})$ & $\langle[0.55,0.65],[0.2,0.35]\rangle$ \\
Certain high $(\mathrm{CH})$ & $\langle[0.65,0.75],[0.1,0.25]\rangle$ \\
\hline
\end{tabular}

$$
\widetilde{W}_{l}=\left[\widetilde{W}_{j l}\right]_{l \times m},
$$

where $\widetilde{W}_{j l}=\left(\left[\mu_{i j}^{-}, \mu_{i j}^{+}\right],\left[v_{i j}^{-}, v_{i j}^{+}\right]\right)$is the $l$ th decision maker's (DM's) judgement on the importance of the $j$ th criteria.

2.2.2. The Expert Judgement Matrix Aggregation. At this point, the expert judgement matrix aggregation was calculated using the following equation:

$$
\begin{aligned}
A= & \operatorname{IIFW} A_{W}\left(A^{(1)}, A^{(2)}, \cdots, A^{(S)}\right) \\
= & \left(\left[1-\prod_{j=1}^{n}\left(1-\mu_{j}^{-}\right)^{w_{j}}, 1-\prod_{j=1}^{n}\left(1-\mu_{j}^{+}\right)^{w_{j}}\right]\right. \\
& \left.\cdot\left[\prod_{j=1}^{n}\left(v_{j}^{-}\right)^{w_{j}}, \prod_{j=1}^{n}\left(v_{j}^{+}\right)^{w_{j}}\right]\right) .
\end{aligned}
$$

$$
\begin{gathered}
E D_{\widetilde{A B}}=\sqrt{\frac{1}{4} \sum_{i=1}^{n}\left[\left(\mu_{A L(X i)}-\mu_{B L(X i)}\right)^{2}+\left(\mu_{A U(X i)}-\mu_{B U(X i)}\right)^{2}+\left(v_{A L(X i)}-v_{B L(X i)}\right)^{2}+\left(v_{A U(X i)}-v_{B U(X i)}\right)^{2}\right]}, \\
H D=\frac{1}{4} \sum_{i=1}^{n}\left[\left|\mu_{A L(X i)}-\mu_{B L(X i)}\right|+\left|\mu_{A U(X i)}-\mu_{B U(X i)}\right|+\left|v_{A L(X i)}-v_{B L(X i)}\right|+\left|v_{A U(X i)}-v_{B U(X i)}\right|\right] .
\end{gathered}
$$

$$
t(x)= \begin{cases}1, & \text { if }|x| \geq \theta \\ 0, & \text { if }|x|<\theta\end{cases}
$$

2.2.6. Relative Assessment (RA) Matrix. At this stage, the RA matrix was calculated through the following equations:

$$
\begin{gathered}
R A=\left[P_{i k}\right]_{n \times m}, \\
P_{i k}=\left(E D_{i}-E D_{K}\right)+\left(t\left(E D_{i}-E D_{K}\right) \times\left(H D_{i}-H D_{K}\right)\right),
\end{gathered}
$$

where $K=\{1,2, \cdots, n\}$ and $t$ is a threshold function which recognizes the equality of the Euclidean distances of two alternatives and defined as
Here, $w_{j}$ can be considered as the ith DM's opinion, 2.2.3. Forming IVIF Weighted Matrix. The IVIF weighted 2.2.4. Determining the Negative Ideal Point. At this step, the negative ideal point was determined using the following equations:

$$
\begin{aligned}
& \widetilde{N S}=\left[\tilde{n}_{j}\right]_{1 \times m}, \\
& \tilde{n} s_{j}=\min _{i} \widetilde{r}_{i j},
\end{aligned}
$$

2.2.5. Calculating Euclidean and Hamming Distance. To calculate the normalized Euclidean distance and the normalized Hamming distance of the alternatives from the Let us assume $\widetilde{A}$ and $\widetilde{B}$ are two IVIF numbers. where $\theta$ is the threshold function that is determined by the decision makers. This parameter is between 0.01 and 0.05 .

2.2.7. Calculating the Assessment Score (AS). Finally, in order to rank the alternatives, the AS for each alternative was calculated as follows:

$$
\mathrm{AS}_{i}=\sum_{k=1}^{n} p_{i k}
$$


2.2.8. Ranking the Alternatives. The ranking of alternatives was based on lowering the assessment score, considering the alternative with the highest assessment score as the most desirable alternative [51].

\section{Case Study}

The proposed approach was used for fire risk assessment in a 166-bed hospital in Shiraz, Iran. This hospital was established in 1963 and had 17 wards. The main activities of this hospital were in the field of obstetrics, neonatology, rheumatology, and neurology. In general, the hospital building does not have an emergency exit door, fire alarm, and extinguishing systems and there is lack of emergency exit signs.

3.1. Results and Discussion. Table 4 shows the identified factors affecting fire risk in the studied hospital.

In order to determine the weight of criteria and subcriteria affecting fire risk, the criteria and subcriteria affecting fire risk were first evaluated using the IFMBWM questionnaire by a panel of ten experts consisting of key members of the Crisis Management Committee with at least one year of experience in hospital. They were asked to compare the importance of each criteria and subcriteria by pairwise comparison of each of the criteria related to probability, severity, and detectability and their subcriteria. Table 5 presents the intuitionistic fuzzy matrix for probability, severity, and detectability criteria. Figure 3 also shows the pairwise comparisons matrix grid for the studied criteria and calculations for subcriteria are similar to the criteria.

Membership grade weights were calculated for the probability, severity, and detectability criteria as follows:

$$
\begin{aligned}
& \operatorname{Min} \xi \\
& \text { s.t. }\left|\frac{\tau_{\mathrm{S}}}{\tau_{\mathrm{P}}}-10\right| \leq \xi, \\
& \left|\frac{\tau_{S}}{\tau_{S}}-0.2\right| \leq \xi, \\
& \left|\frac{\tau_{S}}{\tau_{D}}-8\right| \leq \xi \\
& \left|\frac{\tau_{P}}{\tau_{P}}-0.2\right| \leq \xi, \\
& \left|\frac{\tau_{S}}{\tau_{P}}-10\right| \leq \xi, \\
& \left|\frac{\tau_{D}}{\tau_{P}}-10\right| \leq \xi, \\
& \left(\tau_{P}^{*} \cdot \tau_{S}^{*} \cdot \tau_{D}^{*}\right)=(0.08 \cdot 0.82 \cdot 0.1), \\
& \xi^{*}=0.82
\end{aligned}
$$

The weights of nonmembership for the probability, severity, and detectability criteria were calculated as follows:

$$
\begin{aligned}
& \operatorname{Min} \zeta \\
& \text { s.t. }\left|\frac{\nu_{S}}{\nu_{P}}-0\right| \leq \zeta, \\
& \left|\frac{\nu_{S}}{\nu_{S}}-1.8\right| \leq \zeta, \\
& \left|\frac{v_{S}}{v_{D}}-1\right| \leq \zeta \\
& \left|\frac{\nu_{P}}{\nu_{P}}-1.8\right| \leq \zeta, \\
& \left|\frac{\nu_{S}}{\nu_{P}}-0\right| \leq \zeta \\
& \left|\frac{v_{D}}{v_{P}}-0\right| \leq \zeta, \\
& \left(v_{P}^{*}, v_{S}^{*}, v_{D}^{*}\right)=(0.72,0.12,0.11), \\
& \zeta^{*}=0.11 \text {. }
\end{aligned}
$$
follows:

The final fuzzy and di-fuzzy weight of the criteria is as

$$
\begin{aligned}
W & =\left(W_{P}, W_{S}, W_{D}\right) \\
& =((0.08,0.77),(0.82,0.12),(0.1,0.11)) \\
& =(0.425,0.105,0.47) .
\end{aligned}
$$

Figure 4 presents the weights of fire risk criteria and their subcriteria for the studied hospital.

As can be seen from the subcriteria of probability, severity, and detectability of fire, electrical equipment $\left(W_{P 2}=0.2775\right)$, flammable materials $\left(W_{S 9}=0.26\right)$, and fire alarm system $\left(W_{D 1}=0.4995\right)$ have the highest weight. In the study of $\mathrm{Wu}$ and Tseng conducted in 10 small hospitals with the FAHP method, the hospital protection factor had the highest score [8]. In the study by Jahangiri et al., the most unacceptable risk was in the area of exit routes, considering the NFPA101 method [1]. Javidifar and Mohammadi used the fuzzy AHP method to assess fire risk in hospital facilities and elevators, and the most important fire risk was lack of fire alarm and fire extinguishing systems [52].

Table 6 presents the aggregation matrix of expert opinions and Table 7 shows the weighted decision matrix and negative ideal point for the studied hospital. In Figure 5, the values of the normalized Euclidean distance and the normalized Hamming distance of the hospital wards were presented from the negative ideal point. According to the IVIFCODAS method, the ranking was based on the longest distance from the negative ideal point. As shown in Figure 5, among the different hospital wards, the powerhouse has the 
TABLE 4: Factors affecting fire risk in the studied hospital.

\begin{tabular}{lcc}
\hline Detectability & Probability & Severity \\
\hline D1: fire alarm system & P1: heating systems and heat sources & S1: building features \\
D2: surveillance cameras & P2: electrical equipment and installations & S2: mechanical installations \\
D3: individual report & P3: experience, education, and smoking & P4: instructions \\
& P5: safety inspection and accident reporting system & S4: emergency equipment \\
& P6: housekeeping & S5: safety status of equipment \\
& & S6: emergency preparedness program \\
& S7: flammable materials & S8: the time of the accident \\
& S9: fire place
\end{tabular}

TABLE 5: Intuitionistic fuzzy integrated matrix for fire risk criteria in the studied hospital.

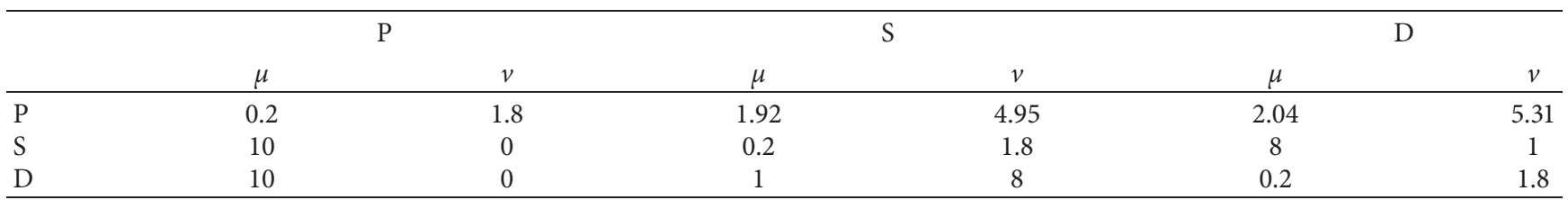

$\mu=$ membership; $v=$ nonmemebership; $\mathrm{P}=$ probability; $\mathrm{S}=$ severity; $\mathrm{D}=$ detectability.

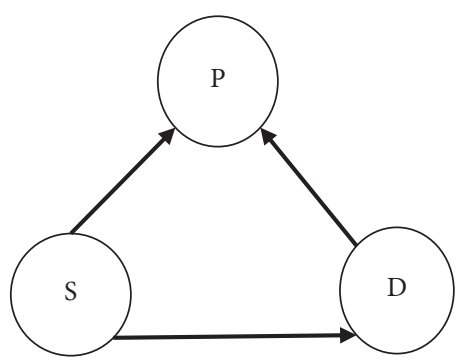

FiguRe 3: Criterion matrix network of fire risk criteria.

most Euclidean and Hamming distance from the negative ideal point.

After calculating and comparing the relative assessment matrix, AS was calculated for all $\theta$ coefficients (0.01 to 0.05$)$ and the values for all $\theta$ were equal to the values shown in Table 8. This table shows the ranking of the hospital wards according to the degree of fire risk. As can be seen, the highest and the lowest fire risks are related to the powerhouse and the supervisor's office, respectively.

According to the results obtained, the powerhouse has the highest fire risk mainly due to the lack of fire extinguishers, no alarms and fire detection systems, being located in the basement floor, boilers and location sensitivity in terms of explosions, inadequate exit, inappropriate housekeeping, and the vicinity of the switchgear with boilers. These results are consistent with the first section, which determines the weight of fire risk subcriteria so that the most important factors affect the fire risk of electrical equipment and installations, proper housekeeping, fire alarm system, flammable materials and emergency preparedness program. Different studies of hospital risk assessment have been conducted in different ratings of fire risk in each ward due to the method of evaluation, the type of the ward and the studied factors $[2,5,12,13,53]$.
In this study, the main reasons for the increase in fire risk are lack of automatic fire alarm systems, lack of fire extinguishers lack of emergency exit stairs, lack of exit routes in wards and insufficient safety signs in the building. These results are consistent with the results of other studies on fire risk assessment in healthcare buildings $[1,2,5,10,12-14,52,54,55]$. For example, Rahmani et al. study, conducted in 2018 using NFPA101 in one of the hospitals in Tehran, showed that the fire risk caused by fire control and extinguishing is unacceptable in all the 30 areas studied, so designing sprinkler systems and standardizing fire control systems are essential to improve fire risk [10].

In our study, there was a slight difference between the fire risk in the powerhouse and the electrical installation room, which is due to the sensitivity of these two locations and the presence of steam boilers and electrical panels. According to our results, among the subcriteria of probability, severity, and detectability of fire, the highest ratings are electrical equipment and installations, flammable materials, and fire alarm systems, respectively. This indicates the importance of fire alarm systems, observing the safety of electrical equipment and installations, and observing the principles of the maintenance and use of flammable materials such as gas oil in the installations.

There was also a significant difference between the risk scores of the institutional and noninstitutional sectors in this study. The reasons for this can be attributed to the increased fire load in the installations due to the existence of boilers and switchboards, the lack of automatic fire alarm and fire extinguishing systems, and the inadequate exit paths. Among the clinical departments, the operation room has the highest fire risk (0.8), due to the location sensitivity of the bar crowd and the inability to leave the building during the fire. The risk of fire in the dormitory and office of the supervisor is low due to the lack of combustion sources and the low fire load.

Our results along with the results of other studies $[10,54,55]$ show that most hospitals lack detection, fire 


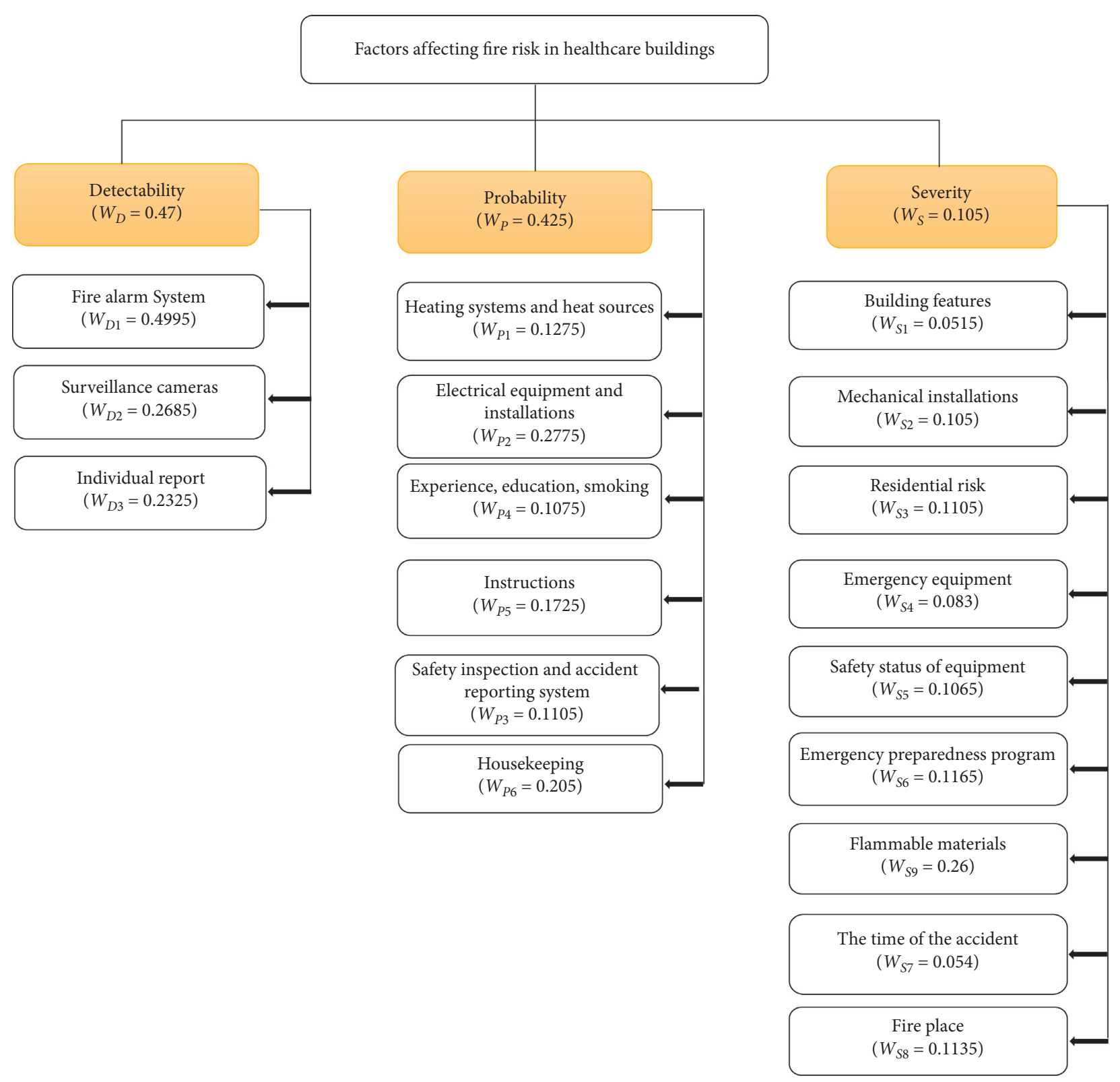

FIGURE 4: Calculated weights for factors affecting fire risk in the studied hospital.

alarm, and automatic extinguishing systems and lack of fire extinguishers. The absence of these systems increases the severity of accidents and increases the duration of detection. As a result, the use of such systems to reduce the amount of casualties and financial losses in hospitals is essential, given the need for automatic fire extinguishing systems in accordance with NFPA101 [56]. On the other hand, it is clear that due to the special conditions of patients, their carrying away from the fire area will not be the only guarantee for their lives and there is a need to provide the best possible follow-up treatment at the time of the accident. Therefore, reducing the likelihood of death of patients undergoing treatment is necessary by predicting the appropriate place to provide treatment at the time of the accident. The hospital management should also agree with other health centers, where necessary, and prepare for the possibility of transferring patients to other centers in the shortest possible time to provide necessary care. 
TABle 6: Aggregation matrix of expert opinions.

\begin{tabular}{lcccccccccccc}
\hline & \multicolumn{4}{c}{ Probability } & \multicolumn{3}{c}{ S } & \multicolumn{3}{c}{ Severity } & \multicolumn{4}{c}{ Detectability } \\
& $\mu-$ & $\mu+$ & $\nu-$ & $v+$ & $\mu-$ & $\mu+$ & $v-$ & $v+$ & $\mu-$ & $\mu+$ & $v-$ & $v+$ \\
\hline Laboratory & 0.44 & 0.32 & 0.56 & 0.48 & 0.43 & 0.32 & 0.57 & 0.50 & 0.43 & 0.32 & 0.57 & 0.50 \\
Powerhouse & 0.46 & 0.35 & 0.54 & 0.47 & 0.33 & 0.18 & 0.67 & 0.58 & 0.31 & 0.15 & 0.69 & 0.59 \\
Emergency & 0.40 & 0.27 & 0.60 & 0.51 & 0.52 & 0.47 & 0.48 & 0.45 & 0.56 & 0.52 & 0.44 & 0.40 \\
Radiology & 0.46 & 0.35 & 0.54 & 0.47 & 0.45 & 0.33 & 0.55 & 0.47 & 0.48 & 0.46 & 0.52 & 0.51 \\
Server room & 0.51 & 0.41 & 0.49 & 0.40 & 0.46 & 0.37 & 0.54 & 0.47 & 0.48 & 0.46 & 0.52 & 0.51 \\
Electrical facilities & 0.49 & 0.39 & 0.51 & 0.44 & 0.35 & 0.19 & 0.65 & 0.55 & 0.32 & 0.16 & 0.68 & 0.58 \\
Dormitory & 0.52 & 0.44 & 0.48 & 0.40 & 0.52 & 0.44 & 0.48 & 0.42 & 0.58 & 0.53 & 0.42 & 0.36 \\
Office supervisor & 0.45 & 0.35 & 0.55 & 0.50 & 0.60 & 0.55 & 0.40 & 0.34 & 0.65 & 0.56 & 0.35 & 0.22 \\
NST & 0.42 & 0.32 & 0.58 & 0.53 & 0.47 & 0.37 & 0.53 & 0.47 & 0.63 & 0.55 & 0.37 & 0.26 \\
NICU2 & 0.38 & 0.25 & 0.62 & 0.55 & 0.41 & 0.26 & 0.59 & 0.50 & 0.55 & 0.52 & 0.45 & 0.42 \\
OB1 & 0.38 & 0.25 & 0.62 & 0.55 & 0.47 & 0.37 & 0.53 & 0.47 & 0.56 & 0.49 & 0.44 & 0.37 \\
Maternity & 0.39 & 0.26 & 0.61 & 0.54 & 0.41 & 0.26 & 0.59 & 0.50 & 0.57 & 0.52 & 0.43 & 0.37 \\
Operation room & 0.39 & 0.27 & 0.61 & 0.54 & 0.41 & 0.26 & 0.59 & 0.50 & 0.51 & 0.47 & 0.49 & 0.46 \\
OB2 & 0.38 & 0.25 & 0.62 & 0.55 & 0.42 & 0.29 & 0.58 & 0.49 & 0.59 & 0.54 & 0.41 & 0.33 \\
NICU1 & 0.38 & 0.25 & 0.62 & 0.55 & 0.45 & 0.32 & 0.55 & 0.46 & 0.56 & 0.53 & 0.44 & 0.39 \\
Neurology and psychiatry & 0.38 & 0.25 & 0.62 & 0.55 & 0.45 & 0.32 & 0.55 & 0.46 & 0.59 & 0.54 & 0.41 & 0.33 \\
Rheumatology & 0.43 & 0.30 & 0.57 & 0.49 & 0.50 & 0.41 & 0.50 & 0.44 & 0.59 & 0.54 & 0.41 & 0.33 \\
\hline
\end{tabular}

TABLE 7: Weighted decision matrix and negative ideal point.

\begin{tabular}{lccccccccccccc}
\hline & \multicolumn{4}{c}{ Probability } & \multicolumn{3}{c}{ Severity } & \multicolumn{4}{c}{ Detectability } \\
& $\mu-$ & $\mu+$ & $v-$ & $v+$ & $\mu-$ & $\mu+$ & $v-$ & $v+$ & $\mu-$ & $\mu+$ & $v-$ & $v+$ \\
\hline Laboratory & 0.503 & 0.398 & 0.057 & 0.049 & 0.500 & 0.403 & 0.466 & 0.410 & 0.866 & 0.841 & 0.232 & 0.041 \\
Powerhouse & 0.517 & 0.425 & 0.055 & 0.048 & 0.411 & 0.279 & 0.549 & 0.472 & 0.837 & 0.801 & 0.282 & 0.048 \\
Emergency & 0.466 & 0.347 & 0.061 & 0.052 & 0.576 & 0.538 & 0.395 & 0.367 & 0.896 & 0.887 & 0.181 & 0.032 \\
Radiology & 0.517 & 0.425 & 0.055 & 0.048 & 0.515 & 0.411 & 0.451 & 0.386 & 0.879 & 0.873 & 0.210 & 0.041 \\
Server room & 0.567 & 0.474 & 0.050 & 0.041 & 0.530 & 0.445 & 0.437 & 0.388 & 0.879 & 0.873 & 0.210 & 0.041 \\
Electrical facilities & 0.543 & 0.458 & 0.052 & 0.045 & 0.427 & 0.290 & 0.533 & 0.449 & 0.840 & 0.804 & 0.278 & 0.048 \\
Dormitory & 0.577 & 0.502 & 0.049 & 0.041 & 0.578 & 0.512 & 0.393 & 0.345 & 0.901 & 0.891 & 0.171 & 0.029 \\
Office supervisor & 0.507 & 0.422 & 0.057 & 0.051 & 0.645 & 0.607 & 0.331 & 0.281 & 0.918 & 0.898 & 0.142 & 0.018 \\
NST & 0.483 & 0.392 & 0.059 & 0.054 & 0.536 & 0.451 & 0.432 & 0.383 & 0.912 & 0.894 & 0.152 & 0.021 \\
NICU2 & 0.446 & 0.329 & 0.064 & 0.056 & 0.482 & 0.355 & 0.482 & 0.406 & 0.894 & 0.888 & 0.183 & 0.034 \\
OB1 & 0.446 & 0.329 & 0.064 & 0.056 & 0.536 & 0.451 & 0.432 & 0.383 & 0.896 & 0.880 & 0.180 & 0.030 \\
Maternity & 0.457 & 0.345 & 0.062 & 0.055 & 0.482 & 0.355 & 0.482 & 0.406 & 0.899 & 0.889 & 0.175 & 0.030 \\
Operation room & 0.458 & 0.350 & 0.062 & 0.055 & 0.482 & 0.355 & 0.482 & 0.406 & 0.885 & 0.875 & 0.200 & 0.037 \\
OB2 & 0.446 & 0.329 & 0.064 & 0.056 & 0.495 & 0.378 & 0.470 & 0.402 & 0.905 & 0.892 & 0.165 & 0.027 \\
NICU1 & 0.446 & 0.329 & 0.064 & 0.056 & 0.519 & 0.405 & 0.448 & 0.378 & 0.898 & 0.889 & 0.177 & 0.032 \\
Neurology and psychiatry & 0.446 & 0.329 & 0.064 & 0.056 & 0.519 & 0.405 & 0.448 & 0.378 & 0.905 & 0.892 & 0.165 & 0.027 \\
Rheumatology & 0.490 & 0.378 & 0.059 & 0.050 & 0.563 & 0.486 & 0.407 & 0.357 & 0.905 & 0.892 & 0.165 & 0.027 \\
Negative ideal point & 0.577 & 0.502 & 0.049 & 0.041 & 0.645 & 0.607 & 0.331 & 0.281 & 0.918 & 0.898 & 0.142 & 0.018 \\
\hline
\end{tabular}

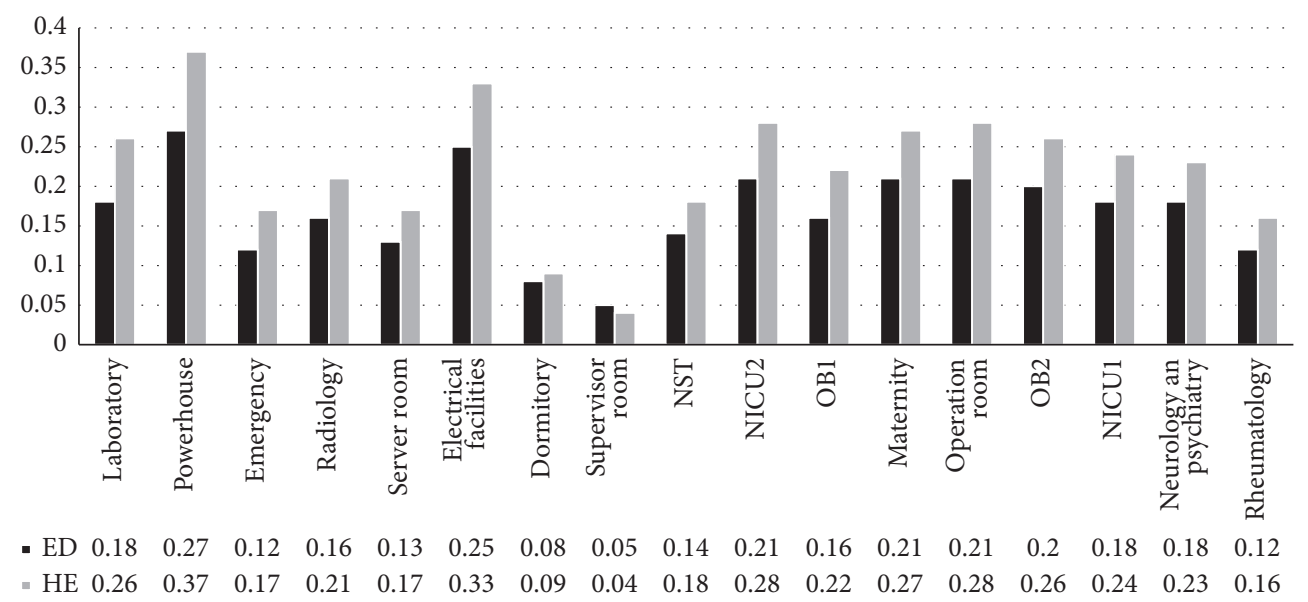

Figure 5: Euclidean (ED) and Hamming (HD) distance values of the studied hospital wards from the negative ideal point. 
TABle 8: Calculated AS and the ranking of the studied hospital wards according to the degree of fire risk $(\Theta=0.01)$.

\begin{tabular}{lcc}
\hline Ward & AS* & Rank \\
\hline Powerhouse & 2.2 & 1 \\
Electrical facilities & 2.1 & 2 \\
Operation room & 0.8 & 3 \\
NICU2 & 0.6 & 4 \\
Laboratory & 0.3 & 5 \\
Maternity & 0.2 & 6 \\
OB2 & -0.2 & 7 \\
Radiology & -0.3 & 8 \\
NICU1 & -0.4 & 9 \\
Server room & -0.8 & 10 \\
OB1 & -0.8 & 11 \\
Neurology and psychiatry & -0.9 & 12 \\
Emergency & -1.3 & 13 \\
NST & -1.7 & 14 \\
Rheumatology & -2.9 & 15 \\
Dormitory & -3.3 & 16 \\
Office supervisor & -4.6 & 17 \\
\hline AS: & &
\end{tabular}

AS: assessment score*.

\section{Conclusion}

The present study investigated the fire risk assessment in healthcare settings by applying FMEA combined with MCDM methods. The theory and innovation contribution of this research can be categorized into the following three sections: the first innovation concerns the use of the BWM method in determining the weight of the severity, probability, and detectability criteria in the FMEA method. A topic that was either overlooked in previous studies [5] or was used by old methods such as AHP [7]. The AHP method has limitations that are eliminated by the BWM method. The second issue is related to the use of the CODAS method to eliminate the limitation of the lack of attention to the indirect relationships between the parameters affecting risk estimation in the FMEA method. Previous studies have simply focused on the RPN score to compare wards [5, 7] and alternatives that we know do not address the indirect relationships. Last, but not least, is the use of intuitionistic fuzzy set to eliminate the limitations of uncertainty in the FMEA method. Previous studies conducted in crisp sets $[5,7]$ or the regular fuzzy sets $[24,29,57]$ were used to model uncertainties. While we know that the intuitionistic fuzzy takes into account the membership degree, the nonmembership degree and the doubt degree, the uncertainty is better modeled. In this study, IVIF is used, which is a combination of intuitionistic fuzzy and type- 2 fuzzy sets that can better model both uncertainty and vagueness. The results of this study showed that using MCDM techniques including BWM in intuitionistic fuzzy sets in combination with the FMEA method can be better and more accurately estimate fire risk in healthcare buildings.

One of the limitations of the research is the lack of measurement of subcriteria due to technical problems. For further studies, fire subcriteria could be measured in detail. Another limitation of the research is that the research was conducted in the intuitionistic fuzzy set; it is suggested that research be performed in other fuzzy sets such as fuzzy rough sets, hesitant fuzzy sets, Pythagorean fuzzy, and neutrosophic sets and the result be compared with this research.

\section{Data Availability}

No data were used in this study. If desired, readers can share their questions with the responsible author.

\section{Disclosure}

This article was extracted from the thesis written by Fateme Omidvari, M.Sc. student of Occupational Health Engineering.

\section{Conflicts of Interest}

The authors declare there are no conflicts of interest regarding the publication of this paper.

\section{Acknowledgments}

The authors would like to thank Hafez Hospital for their invaluable assistance in this article. This article was financially supported by Shiraz University of Medical Sciences, Shiraz, Iran (Grant no. 98-01-04-19656).

\section{References}

[1] M. Jahangiri, F. Rajabi, and F. Darooghe, "Fire risk assessment in the selected hospitals of Shiraz University of Medical Sciences in accordance with NFPA101," Iran Occupational Health Journal, vol. 13, no. 1, pp. 99-106, 2016.

[2] M. Mahdinia, R. Yarahmadi, M. J. Jafari, A. R. Koohpaie, and M. Khazaei, "Fire risk assessment and the effect of emergency planning on risk reduction in a hospital," Qom University of Medical Sciences Journal, vol. 5, no. 3, pp. 71-78, 2011.

[3] R. Campbell, Structure Fires in Health Care Facilities, National Fire Protection Association, Quincy, MA, UAS, 2017.

[4] D. Washington, Hospitals Dont Burn! Hospital Fire Prevention and Evacuation Guide, Pan American Health Organization, Washington, DC, USA, 2014.

[5] S. Kamran, M. Saiedeh, S. Sana, and Z. Ba, "Fire risk management and emergency response planning at Takistan Social Security hospital," in Proceedings of The 1st International Conference on Earthquake, Disaster Management, Rehabilitation and Reconstruction, Qazin Iran, 2016.

[6] M. jahangiri, A. Choobineh, F. Rajabi, and H. S. Nodooshan, Safety and Occupational Health in Hospitals and Health Care Centers, Shiraz University of Medical Sciences, Shiraz, Iran, 2018.

[7] M. Omidvari, N. Mansouri, and J. Nouri, "A pattern of fire risk assessment and emergency management in educational center laboratories," Safety Science, vol. 73, pp. 34-42, 2015.

[8] C. L. Wu and W. W. Tseng, "Development of a fire risk index to evaluate fire safety in Taiwanese small scale hospitals," in Proceedings of the Interflam 2016, London, UK, 2016.

[9] N. Banerjee, S. Chatterjee, and S. Chatterjee, "FireRisk assessment in high rise hospital building in Kolkata: safety issues from ergonomics perspective," in Proceedings of the 13th 
International Ergonomics Conference, Humanizing Work and Work Environment, Mumbai India, 2015.

[10] A. Rahmani and M. Salem, "Fire risk assessment in high-rise hopitalls in accordance with NFPA 101," Revista Latinoamericana de Hipertension, vol. 13, no. 3, pp. 242-245, 2018.

[11] R. Hokmabadi, M. Mahdinia, R. Zaree, M. Mirzaee, and P. Kahsari, "Fire risk assessment by FRAME in a hospital complex," Journal of North Khorasan University of Medical Sciences, vol. 9, no. 2, pp. 173-182, 2017.

[12] E. Habibi and A. Aslsni, "Evaluation of fire risk by FRAME method and studying the effect of trained crisis management team of fire risk level in Hazrat Rasoul-e Akram hospital of Fereydunshahr in 2016," Quarterly Scientific Journal of Rescue and Relief, vol. 9, no. 1, pp. 46-55, 2017.

[13] V. Sarsangi, H. Saberi, M. Malakutikhah, M. Sadeghnia, A. Rahimizadeh, and E. Aboee Mehrizi, "Analyzing the risk of fire in a hospital complex by "fire risk assessment method for engineering"(FRAME)," International Archives of Health Sciences, vol. 1, pp. 9-13, 2014.

[14] R. Yarahmadi, A. Gholizade, M. Jafari, A. Kohpae, and M. Mahdinia, "Performance Assessment and analysis of national building codes with fire safety in all wards of a hospital," Iran Occupational Health Journal, vol. 6, no. 1, pp. 28-36, 2009.

[15] H.-C. Liu, L. Liu, and N. Liu, "Risk evaluation approaches in failure mode and effects analysis: a literature review," Expert Systems with Applications, vol. 40, no. 2, pp. 828-838, 2013.

[16] R. Khasha, M. M. Sepehri, and T. Khatibi, "A fuzzy FMEA approach to prioritizing surgical cancellation factors," International Journal of Hospital Research, vol. 2, no. 1, pp. 17-24, 2013.

[17] M. Omidvar and F. Nirumand, "Risk assessment using FMEA method and on the basis of MCDM, Fuzzy logic and Grey theory-a case study of overhead cranes," Journal of Health and Safety at Work, vol. 7, no. 1, pp. 63-76, 2017.

[18] M. SarAbadani and S. Ghiyasi, "Identification of health, safety, and environment aspects and hazards in loghman hospital and manage of their risks using analytical hierarchy process technique," International Archives of Health Sciences, vol. 5, no. 3, pp. 86-92, 2018.

[19] J. Rezaei, "Best-worst multi-criteria decision-making method," Omega, vol. 53, pp. 49-57, 2015.

[20] S.J. Ghoushchi, M. Khazaeili, A. Amini, and E. Osgooei, "Multi-criteria sustainable supplier selection using piecewise linear value function and fuzzy best-worst method," Journal of Intelligent \& Fuzzy Systems, vol. 37, no. 2, pp. 2309-2325, 2019.

[21] W. Song, J. Li, H. Li, and X. Ming, "Human factors risk assessment: an integrated method for improving safety in clinical use of medical devices," Applied Soft Computing, vol. 86, no. 1, p. 105918, 2020.

[22] M. J. Rezaee, S. Yousefi, M. Eshkevari, M. Valipour, and M. Saberi, "Risk analysis of health, safety and environment in chemical industry integrating linguistic FMEA, fuzzy inference system and fuzzy DEA," Stochastic Environmental Research and Risk Assessment, vol. 34, no. 1, pp. 201-218, 2020.

[23] D. S. Chang, J. H. Chung, K. L. Sun, and F. C. Yang, "A novel approach for evaluating the risk of health care failure modes," Journal of Medical Systems, vol. 36, no. 6, pp. 3967-3974, 2012.

[24] N. Chanamool and T. Naenna, "Fuzzy FMEA application to improve decision-making process in an emergency department," Applied Soft Computing, vol. 43, no. 1, pp. 441-453, 2016.
[25] C. Dağsuyu, E. Göçmen, M. Narlı, and A. Kokangül, “Classical and fuzzy FMEA risk analysis in a sterilization unit," Computers \& Industrial Engineering, vol. 101, no. 1, pp. 286-294, 2016.

[26] A. Jamshidi, S. A. Rahimi, D. Ait-Kadi, and A. Ruiz, "A comprehensive fuzzy risk-based maintenance framework for prioritization of medical devices," Applied Soft Computing, vol. 32, no. 1, pp. 322-334, 2015.

[27] H.-C. Liu, X.-J. Fan, P. Li, and Y.-Z. Chen, "Evaluating the risk of failure modes with extended MULTIMOORA method under fuzzy environment," Engineering Applications of Artificial Intelligence, vol. 34, no. 1, pp. 168-177, 2014.

[28] Q.-L. Lin, D.-J. Wang, W.-G. Lin, and H.-C. Liu, "Human reliability assessment for medical devices based on failure mode and effects analysis and fuzzy linguistic theory," Safety Science, vol. 62, no. 1, pp. 248-256, 2014.

[29] H.-C. Liu, L. Liu, N. Liu, and L.-X. Mao, "Risk evaluation in failure mode and effects analysis with extended VIKOR method under fuzzy environment," Expert Systems with Applications, vol. 39, no. 17, pp. 12926-12934, 2012.

[30] H.-C. Liu, J.-X. You, X.-Y. You, and M.-M. Shan, "A novel approach for failure mode and effects analysis using combination weighting and fuzzy VIKOR method," Applied Soft Computing, vol. 28, no. 1, pp. 579-588, 2015.

[31] H.-C. Liu, J.-X. You, and X.-Y. You, "Evaluating the risk of healthcare failure modes using interval 2-tuple hybrid weighted distance measure," Computers \& Industrial Engineering, vol. 78, no. 1, pp. 249-258, 2014.

[32] H.-C. Liu, J.-X. You, and C.-Y. Duan, "An integrated approach for failure mode and effect analysis under intervalvalued intuitionistic fuzzy environment," International Journal of Production Economics, vol. 207, no. 1, pp. 163-172, 2019.

[33] S. Dorosti, M. Fathi, S. J. Ghoushchi, M. Khakifirooz, and M. Khazaeili, "Patient waiting time management through fuzzy based failure mode and effect analysis," Journal of Intelligent \& Fuzzy Systems, vol. 38, no. 6, pp. 1-12, 2020.

[34] K. T. Atanassov, "Intuitionistic fuzzy sets," Fuzzy Sets and Systems, vol. 20, no. 1, pp. 87-96, 1986.

[35] L. A. Zadeh, "Fuzzy sets," Information and Control, vol. 8, no. 3, pp. 338-353, 1965.

[36] H. Mishi mast nehi, A. A. Nora, and S. Rezaine Nasab, "Intuitive fuzzy numbers and actions on them," in Proceedings of the Sixth National Conference on Intelligent Systems, Kerman, Iran, 2004.

[37] M. K. Ghorabaee, E. K. Zavadskas, Z. Turskis, and J. Antucheviciene, "A new combinative distance-based assessment (CODAS) method for multi-criteria decision making Economic Computation \& Economic Cybernetics," Studies \& Research, vol. 50, no. 3, pp. 25-44, 2016.

[38] M. A. Hassanain, M. A. Hafeez, and M. O. Sanni-Anibire, "A ranking system for fire safety performance of student housing facilities," Safety Science, vol. 92, pp. 116-127, 2017.

[39] F. Liu, S. Zhao, M. Weng, and Y. Liu, "Fire risk assessment for large-scale commercial buildings based on structure entropy weight method," Safety Science, vol. 94, pp. 26-40, 2017.

[40] J. Pushkina, V. Jansons, and K. Didenko, "Applying multicriteria analysis methods for fire risk assessment," Safety of Technogenic Environment, vol. 7, no. 1, pp. 42-47, 2015.

[41] Y.-y. Wei, J.-y. Zhang, and J. Wang, "Research on building fire risk fast assessment method based on fuzzy comprehensive evaluation and SVM," Procedia Engineering, vol. 211, no. 1, pp. 1141-1150, 2018. 
[42] A. Arborea, G. Mossa, and G. Cucurachi, "Preventive fire risk assessment of italian architectural heritage: an index based approach," Key Engineering Materials, Trans Tech Publications, Moscow, Russia, 2015.

[43] H. Hai-yun, "Research on standardization method of risk assessment for fire public liability insurance in assembly occupancies and underwriting auditing," Procedia Engineering, vol. 11, pp. 120-126, 2011.

[44] Y.-x. Guan, Z. Fang, and T.-r. Wang, "Fire risk assessment and daily maintenance management of cultural relic buildings based on ZigBee technology," Procedia Engineering, vol. 211, pp. 192-198, 2018.

[45] L. Dunwen, Y. Lei, and L. Bo, "Fuzzy-entropy theory comprehensive evaluation method and its application in building construction safety," Procedia Engineering, vol. 43, pp. 137$142,2012$.

[46] Education MoHaM. Standards for Planning and Design of Safe Hospitals. Tenth Volume: General Requirements. Deputy for Management and Resource Development Office of Physical Resources Development and Civil Affairs: Deputy for Management and Resources Development, 2013.

[47] National Building Regulations of Iran, The third Topic. Protection of Buildings Against Fire, 2013.

[48] Q. Mou, Z. Xu, and H. Liao, "An intuitionistic fuzzy multiplicative best-worst method for multi-criteria group decision making," Information Sciences, vol. 374, pp. 224-239, 2016.

[49] L. Abdullah and L. Najib, "Sustainable energy planning decision using the intuitionistic fuzzy analytic hierarchy process: choosing energy technology in Malaysia," International Journal of Sustainable Energy, vol. 35, no. 4, pp. 360-377, 2016.

[50] E. Boltürk and C. Kahraman, "Interval-valued intuitionistic fuzzy CODAS method and its application to wave energy facility location selection problem," Journal of Intelligent and Fuzzy Systems, vol. 35, no. 4, pp. 4865-77, 2018.

[51] F. B. Yeni and G. Özçelik, "Interval-valued Atanassov intuitionistic Fuzzy CODAS method for multi criteria group decision making problems," Group Decision and Negotiation, vol. 28, no. 2, pp. 433-452, 2019.

[52] M. Javidifar and Y. Mohammadi, "Fire safety and risk assessment of hospital facilities and elevators using MCE method in fuzzy environment (Jam Hospital case study)," in Proceedings of The 3rd National Conference on Urban Safety and Fire Service, Tehran, Iran, 2017.

[53] A. Rahouti, S. Datoussaïd, and R. Lovreglio, "A sensitivity analysis of a hospital evacuation in case of fire," in Proceedings of the Fire and Evacuation Modelling Technical Conference, Málaga, Spain, 2016.

[54] Z. Zamanian, M. Evazian, I. Hazeghi, and H. Daneshmandi, "Fire safety status in the hospitals of Shiraz university of medical Sciences, Shiraz, Iran," International Journal of Occupational Hygiene, vol. 5, no. 3, pp. 96-100, 2013.

[55] E. Habibi, B. Soleymani, R. Nateghi, R. Lotfi, and M. Yarmohammadian, "Risk management in radiology units of Isfahan university of medical science' hospital," Health Information Management, vol. 4, no. 1, pp. 133-141, 2007.

[56] Alternative Approaches to Life Safety Guide on NFPA 101A, 2007.

[57] H. Liu, X. Deng, and W. Jiang, "Risk evaluation in failure mode and effects analysis using fuzzy measure and fuzzy integral," Symmetry, vol. 9, no. 8, p. 162, 2017. 